\title{
Government and school community member perception on childhood obesity prevention in the primary school settings of Brunei Darussalam
}

\author{
Siti Rohaiza Ahmad ${ }^{1,2 *}$, Lisa Schubert², Robert Bush²
}

'Universiti Brunei Darussalam, PAPRSB Institute of Health Science, Jalan Tungku Link, BE1410, Brunei Darussalam, ${ }^{2}$ Faculty of Medicine, The University of Queensland, School of Public Health, Herston, Qld 4006, Australia

\begin{abstract}
Introduction: Childhood obesity is increasing in the Southeast Asian region, including in the nation of Brunei Darussalam. Within the public health focus on obesity prevention, specific settings, including primary schools, have been singled out as suitable sites for action. Recognizing that stakeholders are, in their various roles, producers of policy and/or implementers of practice, the purpose of this study in Brunei was to establish a baseline for interventions as well as to establish strengths and limitations in the current practice.
\end{abstract}

Methods: Semi-structured interview with government and school community stakeholders was conducted, and transcriptions were thematically analyzed.

Results: Three themes emerged from the data. The first theme was "children's eating habits today = healthy adult population tomorrow;" many of the stakeholders believed that, if healthy eating is not practiced from an early stage, this can lead to the development of harmful diet-related diseases in the future. The second theme was "barriers to effectively addressing the issue of childhood obesity;" all were able to identify barriers such as workforce issues to address obesity prevention and health promotion activities. The third theme was "parental responsibility for children's diet and physical activity habits." The majority of respondents believed that parents are responsible for the rise in childhood obesity in Brunei.

Conclusions: The widespread ethos of personal responsibility for health behaviors has resulted in policies having a heavy emphasis on individual health behavior management and blame for the problem being directed primarily at parents. This individualization of the problem of childhood obesity is a barrier to the planning and implementation of ecological interventions.

Key words: Childhood obesity; stakeholders; diet; physical activity; primary schools

*Corresponding author: S. R. Ahmad, Lecturer, PAPRSB Institute of Health Science, University Brunei Darussalam, Brunei Darussalam. Phone: +6732463001. Fax: +6732461081.

E-mail: Rohaiza.ahmad@ubd.edu.bn

Submitted: 13 September 2018/Accepted: 9 December 2018

DOI: https://doi.org/10.17532/jhsci.2018.191

UNIVERSITY OF SARAJEVO FACULTY OF HEALTH STUDIES

\section{INTRODUCTION}

Childhood obesity is increasing globally $(1,2)$. The International Obesity Task Force has reported that about $10 \%$ of school-aged children $(5-17$ years old) worldwide are found to be overweight, and of that $10 \%$, a quarter are in the obese category (3). 
Countries in the Southeast Asian (SEA) region, including Brunei, are also recording an upward trajectory in childhood obesity rates (4). Within the SEA region, the number of children who are obese had recorded an increase from 1.2 million in 1990 to 2.5 million in 2010 (5). The prevalence of childhood obesity in the Brunei primary schools shows an increasing trend from $11.8 \%$ in 2005 to $17.3 \%$ in 2013 (6). Without proper obesity prevention policies and programs, health problems caused by childhood obesity are likely to persist into adulthood (7). The consequences of obesity are detrimental to the country's economic development, not the least of which is the increased need to provide medical specialists and other hospital services $(8,9)$.

Increasing attention has been placed on healthy diet promotion as well as obesity prevention within specified settings to curb future upward trajectories in the prevalence of childhood obesity. One such setting for obesity prevention is schools $(10,11)$. It has been shown that school-based prevention can be effective in preventing excessive weight gain in children and also in reducing the number of overweight and obese children (12). School-based interventions incorporating the involvement of parents and the surrounding community have been shown to contribute to more positive impact to the programs (12).

The rationale for school-based health promotion activities is well established. Since childhood is a time of habit formation and most children regularly spend a significant proportion of their time over a number of years within the school environment, it is reasonable to suggest that this environment has the potential to influence their habits, including diet and physical activity. Schools can provide a positive environment conducive to promoting social interactions among students, teachers, parents, and other members of the school community $(13,14)$. The school and school neighborhood food and built environments, school facilities, curriculum, and the school community can all play a role in shaping children's food and physical activity habits (15).

Recognizing that stakeholders are, in their various roles, producers of policy and/or implementers of practice in Brunei, the purpose of this study was to explore stakeholder perceptions of contributing factors to childhood overweight and obesity, to establish strengths and limitations in current obesity prevention practice, and to identify possible future directions to strengthen the school-based response to obesity.

\section{METHODS}

Central ethical approval was obtained from The University of Queensland Human Ethics Committee (Ethics application no. 2012000915). Approval was obtained from the main gatekeeper, the Director of School, Ministry of Education, and Ministry of Health $(\mathrm{MOH})$, Brunei Darussalam. Semi-structured interviews were conducted with selected individuals from government agencies and school community members $(16,17)$. To obtain perspectives from the various key players involved in the primary school-based obesity intervention policies in Brunei, representatives from key government agencies were purposively selected. More than one individual from a stakeholder group was interviewed because as more interviews are conducted, the interviewer can build on issues raised in earlier interviews (18). The main informants selected were stakeholders responsible for policy writing and policy implementation at the government agency level of operation, as well as a sample of school stakeholders who were directly observing consequences of policy. A checklist (i.e., a list of interview questions to trigger discussion) was used during the face-to-face semi-structured interviews to ensure in-depth questioning while staying focused on the subject $(18,19)$. Findings from government agency representatives and adult school stakeholder interviews (parents, teachers, principals, and canteen operators) are reported in this paper. Children's views have been reported elsewhere (20).

Interviews were conducted at a time and place convenient to the stakeholders, mainly at their workplace and during office hours. The time frame to complete all interviews (November 2012-May 2013) was kept to a minimum to avoid issues associated with policy changes over time. Interviews lasted between 60 and $90 \mathrm{~min}$. Interviews were transcribed verbatim into a word document and names were removed to protect confidentiality and anonymity. Transcribed data were transferred into QSR NVivo 11 (21) to assist with data coding and 
analysis. Thematic analysis was used because it is suitable for analyzing a large amount of raw qualitative data (22). The first few transcriptions were coded independently by a second researcher, who was also involved in later stages of analysis and final interpretation of the data to enhance data trustworthiness (23).

\section{RESULTS}

Individual interviews were conducted with 17 stakeholders: 6 of these were from various health and education government agencies and 11 were school community members (5 principals and 6 teachers). In summary, the main key informants selected were as follows:

- Stakeholder responsible for setting policy:

Members of the section under the $\mathrm{MOH}$ dealing with organizing the promotion of physical activity and healthy eating programs

Government officer holding a senior position.

- Stakeholders responsible for the implementation of policy:

Members of the section under the MOE dealing mainly with checking school canteen

Nurses who conducted health checks in the schools

Doctors (who treat obese/overweight children in the obesity clinic but not directly involved in the implementation of policy)

Member of the section under the MOE involved with writing syllabus on healthy eating and physical activity topics

Members of the section under the MOE that organizes various sport activities.

The three major themes that arose were Children's eating habits today = healthy adult population tomorrow, barriers to effectively addressing the issue of childhood obesity, and parental responsibility for children's diet and physical activity habits.

The first theme was "Children's eating habits today = healthy adult population tomorrow." When asked about the importance of healthy eating and physical activity for children, all stakeholders rated the issue high in importance. Many of them believed that, if healthy eating is not practiced from an early stage, this can lead to the development of harmful diet-related diseases in the future. Subsequently, preventative measures were widely endorsed, as illustrated by this quote:

"If primary school age children understand and practice healthy eating, it will become the lifestyle for the whole country." (Teacher).

While it might be expected that the same perspective (the predisposition to harmful diet-related diseases in the future) was also held by stakeholders who were working in the field of health, stakeholders from the education department also shared similar views:

Into my understanding and of course, the effect you do not really see it now, you might see it now, most probably if you are really inactive or you are not really looking after your diet, that kind of thing, it's very important. But if you constantly, regularly, not really watching over what you eat and do not constantly do exercise it might lead to, what you call that... health issues in the future. (Staff from the Education Ministry involved in writing syllabuses for textbooks).

For some, such as the school nurses, while they were very much aware of the issue of childhood obesity and overweight, it was only one of the several health issues which was a consideration in planning what to prioritize in their work with school-age children:

Right now we are mainly focussing on their physical state. As long as their body is healthy. It's our part to check their weight and height, whether their development is going well. After that, we also check their eyes, whether they have good vision or not. If not, we refer them to eye clinic. We do all the physical checks together. (School health nurses).

The second theme was "Barriers to effectively addressing the issue of childhood obesity." During the interviews, all stakeholders were able to identify barriers. For example, the most common issue across the ministries and schools communities was a lack of workforce to address obesity prevention and health promotion activities, a lack of specialization of teachers to deliver obesity prevention and health promotion activities, competing commitments/ priorities in the schools, low parent engagement in school-based obesity prevention and health promotion activities, and a lack of facilities to conduct school-based activities. Most stakeholders alleged that the impact of these limitations reduced individual schools' capability to contribute to the issue of childhood-obesity intervention. 
The teachers might just want to do it but (were) overloaded with their core business of making sure the children achieve their level of academic requirements or whatever (Member of the $\mathrm{MOH}$ section responsible for organizing the promotion of physical activity and healthy eating programs).

School principals recognized that they had a major role in the prevention of childhood obesity in Brunei. One principal acknowledged that providing education to children was relatively easy, but changing their attitudes was difficult. They also thought that the often non-continuous nature of school obesity programs meant that these programs fail to achieve the desired attitude change results.

The third theme was "Parental responsibility for children's diet and physical activity habits." A majority of the stakeholders, from both the health and education departments, as well as teachers, believed that parents are responsible for the rise in childhood obesity in Brunei and that it was parents' role to address the problem. The main reason provided for this attitude was that, while children are growing up, they spend most of their time under the care of their parents. Parents were seen as having an important role in shaping dietary habits in the home environment and this was seen as the strongest influence on children's habits, even more so than any genetic influence. Some respondents believed that many parents were happy as long as their child ate something and were less concerned about the quality of their children's diet. This was put down to being unaware of the consequences of allowing children to consume an unrestricted diet. Parents themselves also believed that children in Brunei were more likely to develop obesity when parents and immediate family members, such as siblings and grandparents, were also overweight or obese. Some school health nurses shared examples where some parents were unsupportive of the efforts of doctors and nurses from the obesity clinic to help their obese or overweight child.

Sometimes I see parents, like yesterday, I think his child was only Primary 1, told him to go with his child to see the doctor, but he refused to come inside the doctor's room and said that her child could talk to the doctor herself. (School health nurse)

While doctors from the obesity clinic focused on treatment, their involvement in assessing overweight and obese children and providing counseling to the parents of children referred to the clinic made them valuable informants. Their view of the main driver of obesity in Brunei was that the poor level of parental awareness and their low prioritization of obesity interventions, as evidenced by non-attendance at scheduled clinic appointment and perceived failure to implement home-based intervention plans, were primarily responsible. These specialist doctors also believed that there was an inaccurate perception among some parents of obese children that "children will get better when they get older". Which means that their child's weight problem would simply go away with time and that no particular action need therefore be taken. The doctors also expressed concern that obese parents provided a poor role model for their children.

While school principals' generally considered that the school had a role to play in education about obesity prevention, teachers were more circumspect. Teachers believed that parents should be made more aware of the importance of healthy eating and physical activity. Due to other work commitments and priorities, some teachers believed that they themselves are not responsible for conducting programs related to healthy eating and that it should be the full responsibility of the $\mathrm{MOH}$.

[The] Health ministry [should] handle the situations rather than teachers, this is due to our workloads and time limitation to carry out the programs. (Primary school teacher, large residential village school)

This teacher believed this to be a misguided view of the role of nutrition. However, some of the respondents also believed that the issue of childhood obesity is also the responsibility of everyone, including government ministries, heads of villages, and local communities.

There was some awareness about the current government rules and regulations, relating to childhood obesity intervention programs in the school such as the structured physical education classes, healthy canteen guidelines in the primary schools, and weekly aerobic classes on Saturday. However, many of the stakeholders from outside the school community realized that it is highly dependent on the effort and creativity of the principal and teachers within a particular school to organize the obesity prevention 
programs. Teachers expressed varied ideas regarding ways they could implement strategies to promote healthy eating practices in their school settings. These includes having in-school fruit and vegetable gardens as part of students' activities. Apart from that, teachers also incorporated information about fruits and vegetables in their lessons.

\section{DISCUSSION}

Previous research has shown that the school community members, particularly teachers, have the power to influence children's habits (24). Based on this stakeholder analysis, childhood obesity prevention programs in Brunei schools have been considered non-core business by the school community members. Previous studies reported that too much focus on academic achievement impeded efforts at health promotion in schools (25), which is what has been observed in Brunei. The importance of healthy eating and physical activities among children was recognized by both the government and school community members. A lack of budget and workforce to support childhood obesity prevention programs were other main issues faced by the school administration. These are common barriers that have been noted in other childhood obesity prevention programs $(26,27)$. Without sufficient budgetary support and an adequate trained workforce to assist schools to address the problem, it is unlikely that the situation will change in Brunei.

Enhancing the current roles of various stakeholders has been proposed widely in the literature. Earlier research has lauded the role of teachers in the role of disease prevention in the school setting $(14,28)$, and core primary school curriculum in many countries supports this. Teachers and school health nurses need to be provided training so that they can take up their role in promoting healthy eating and physical activity (29). Training is also important to prevent undesirable actions, such as stigmatization of those children who have been identified as overweight or obese $(30,31)$. As shown in this research, teachers can play a very important role in contributing to the obesity prevention programs in school settings, but further support for teachers needs to be provided to support them in this endeavor.
However, in addition to the emphasis on the role of the teachers and school health nurses in the school to support school-based obesity prevention programs, a supportive infrastructure and resources are also required (32). For example, lesson learnt from the school food policy programs in the US has demonstrated that the provision of financial resources from the government or private institution for programs evaluation has helped to shape policy, leading to positive changes to the food and beverages sold in school setting (33). The design of the school-based program also plays a very important role to ensure its effectiveness. For example, longterm and intensive interventions are very demanding as it requires financial and human resources; therefore, sustainability is vital. Apart from that, the nature of the program also plays a very important role, i.e., multi-component or comprehensive programs have been found to be more successful and have shown promising results. Despite that, however, single-focused intervention such as a ban of unhealthy snacks in the school settings was much easier to implement and evaluate (34).

The stakeholders from the health and education sectors believed that parents were responsible for the childhood obesity issue in Brunei. Previous studies involving parents in other populations have also shown that there is a high level of blame aimed at parents and this has become a considerable obstacle to curbing childhood obesity (35-37). In fact, certain childhood obesity prevention programs were mainly focused on parents (38). The parents' role, therefore, is heightened and scrutinized in the prevention of childhood obesity. However, blaming particular individuals, such as parents, for childhood obesity may be perceived as a potential barrier to prevention measures. These beliefs may have an impact on the policy focus and compromise the support from other parties to address the problems of childhood obesity (39-41). The widespread practice of the individualization of childhood obesity as a problem has resulted in delayed focus or neglect toward other contributing factors, including the school neighborhood nutrition environment and food marketing targeting children $(36,42)$. Parents themselves may also feel victimized and guilty, which may affect their feeling of accountability and obligations to take care of their children's health (43). 
A mindset more conducive to successful planning is to perceive childhood obesity as a multisectoral responsibility (27). A multisectoral approach encompasses all aspects of social characteristics such as family eating styles, community features such as food availability, and government involvement such as implementation of food and nutrition policies (44). A multisectoral approach to childhood obesity prevention requires a well-coordinated, continuous, and long-term implementation to ensure success (45). Several elements that needed to be considered to ensure the success of the large-scale childhood obesity prevention have been illustrated in previous research. Such programs require strong leadership, effective communication between the key players, budgeting, and prioritization of tasks $(27,46)$. Furthermore, implementation needs to be monitored effectively using reliable data sources and published reports. The outcome of the implementation, in this case, whether there is an improvement in terms of the practice of healthy eating and physical activity needed to be measured as well. There are some challenges to measure the success of the implementation, such as effectiveness in dissemination of the measuring tools and responses to the questionnaires (47).

\section{CONCLUSIONS}

There is a growing view in public health that childhood obesity prevention should be seen as a multifactorial problem, which requires shared responsibility, and multiple complementary strategies. While stakeholders identified with primary school settings in Brunei Darussalam hold views opposing this, it will act as a significant barrier to implement evidence-based obesity prevention policy.

Ideally, collaborations between school teachers and school health nurses with health promotion and public health professionals in the prevention of childhood obesity using an integrated Health Promoting Schools approaches have the greatest potential to achieve gains. School community members including school administrators, school health nurses, and teachers are placed in key roles to influence diet and physical activity of children but are currently under-resourced to maximize their impact. Using an individual responsibility approach to understand attribution of responsibility for the problem of childhood overweight and obesity results in policies placing a heavy bias towards individual management of the problem, and blame for the problem being directed primarily at parents. This limited way of understanding the problem is a barrier to effective action. However, despite the emphasis on the role of the school community members to support school-based obesity intervention programs, a supportive infrastructure and resources are required to ensure the effectiveness of the programs in the school setting.

Future research involving the immediate family members may help in discovering other factors that might contribute to childhood obesity among Bruneian children. Previous research has indicated that immediate family members and caregivers, such as siblings and grandparents, also play a very important role in affecting healthy eating and physical activity habits $(48,49)$. In addition, other country studies of stakeholder perspectives and obesity policy will assist to better understand barriers to progress.

\section{ACKNOWLEDGMENTS}

The authors wish to thank the $\mathrm{MOH}$ and Ministry of Education of Brunei Darussalam for the cooperation and permission to conduct the interviews. The research was conducted while SRA was a $\mathrm{PhD}$ Scholar ( $\mathrm{PhD}$ education was fully sponsored by the Brunei Government) at the University of Queensland.

\section{CONFLICTS OF INTEREST}

The authors declare that they have no conflicts of interest.

\section{REFERENCES}

1. Karnik S, Kanekar A. Childhood obesity: A global public health crisis. Int J Prev Med 2012;3:1-7.

2. Department of Statistics. Labour Force Survey 2014 Report. Brunei Darussalam: Prime Minister's Office; 2014.

3. Khambalia AZ, Dickinson S, Hardy LL, Gill T, Baur LA. A synthesis of existing systematic reviews and meta-analyses of school-based behavioural interventions for controlling and preventing obesity. Obes Rev 2012;13(3):214-33.

https://doi.org/10.1111/j.1467-789X.2011.00947.x

4. $\mathrm{MOH}$. Health Promotion Blueprint 2011-2015: Ministry of Health. Brunei 
Darussalam: Bandar Seri Begawan; 2011.

5. de Onis M, Blössner M, Borghi E. Global prevalence and trends of overweight and obesity among preschool children. Am J Clin Nutr 2010;92(5):1257-64

https://doi.org/10.3945/ajcn.2010.29786.

6. Hawkes C, Ahern AL, Jebb SA. A stakeholder analysis of the perceived outcomes of developing and implementing England's obesity strategy 2008-2011. BMC Public Health 2014;14(1):441.

https://doi.org/10.1186/1471-2458-14-441.

7. Lloyd LJ, Langley-Evans SC, McMullen S. Childhood obesity and risk of the adult metabolic syndrome: A systematic review. Int J Obes (Lond) 2012;36(1):1-11

https://doi.org/10.1038/ijo.2011.186.

8. Selassie M, Sinha AC. The epidemiology and aetiology of obesity: A global challenge. Best Pract Res Clin Anaesthesiol 2011;25(1):1-9.

https://doi.org/10.1016/j.bpa.2011.01.002.

9. Withrow D, Alter DA. The economic burden of obesity worldwide: A systematic review of the direct costs of obesity. Obes Rev 2011;12(2):131-41.

https://doi.org/10.1111/j.1467-789X.2009.00712.x.

10. Foster GD, Sherman S, Borradaile KE, Grundy KM, Vander Veur SS, Nachmani J, et al. A policy-based school intervention to prevent overweight and obesity. Pediatrics 2008;121(4):e794-802.

https://doi.org/10.1542/peds.2007-1365.

11. Story M. School-based approaches for preventing and treating obesity. Int J Obes Relat Metab Disord 1999;23 Suppl 2:S43-51. https://doi.org/10.1038/sj.ijo.0800859.

12. Wang $Y$, Wu Y, Wilson RF, Bleich S, Cheskin L, Weston C, et al. Childhood Obesity Prevention Programs: Comparative Effectiveness Review and Meta-Analysis. Rockville (MD): Agency for Healthcare Research and Quality (US); 2013.

13. Adams K. Behaviour for Learning in the Primary School. Exeter: Learning Matters Ltd.; 2010. Available from: http://www.UQL.eblib.com.au/patron/ FullRecord.aspx? $=686458$. [Last accessed on 2018 Oct 10].

14. Hernandez BL. Health, physical activity, and academic achievement: The role of teachers, schools, and communities. J Phys Educ Recreat Dance 2014;85(3):8-10.

https://doi.org/10.1080/07303084.2014.876868.

15. Sun MC, Lalsing $Y$, Subratty AH. Primary school food environment in Mauritius. Nutr Food Sci 2009;39(3):251-9.

https://doi.org/10.1108/00346650910957500.

16. Morse JM. Researching illness and injury: Methodological considerations. Qual Health Res 2000;10(4):538-46.

https://doi.org/10.1177/104973200129118624.

17. Sandelowski M. Reembodying qualitative inquiry. Qual Health Res 2002;12(1):104-15.

https://doi.org/10.1177/1049732302012001008.

18. Hansen E. Successful Qualitative Health Research. New South Wale, Australia: Allen and Unwin; 2006

19. Varvasovszky Z, Brugha R. A stakeholder analysis. Health Policy Plan 2000;15(3):338-45.

https://doi.org/10.1093/heapol/15.3.338.

20. Ahmad SR. Diet and Physical Activity Environments in Primary Schools in Brunei Darussalam A Thesis; 2016.

21. Qualitative Solutions and Research International. NVivo 11 for Windows 2016. Available from: http://www.qsrinternational.com/nvivo-product/nvivo11-for-windows. [Last accessed on 2018 Oct 12].

22. Braun V, Clarke V. Using thematic analysis in psychology. Qual Res Psychol 2006;3(2):77-101. https://doi.org/10.1191/1478088706qp063oa

23. Pope C, Ziebland S, Mays N. Qualitative research in health care. Analysing qualitative data. BMJ 2000;320(7227):114-6

https://doi.org/10.1136/bmj.320.7227.114.

24. Eliassen $E$. The impact of teachers and families on young children's eating behaviors. YC Young Chil 2011;66(2):84-9.

25. Morgan P. Teacher perceptions of physical education in the primary school: Attitudes, values and curriculum preferences. Phys Educ 2008;65(1):46-56.

26. Barry CL, Brescoll VL, Gollust SE. Framing childhood obesity: How individualizing the problem affects public support for prevention. Polit Psychol 2013;34(3):327-49

https://doi.org/10.1111/pops.12018.

27. Clarke JL, Griffin TL, Lancashire ER, Adab P, Parry JM, Pallan MJ, et al. Parent and child perceptions of school-based obesity prevention in England: A qualitative study. BMC Public Health 2015;15(1):1224. https://doi.org/10.1186/s12889-015-2567-7.

28. Smolak L, Harris B, Levine MP, Shisslak CM. Teachers: The forgotten influence on the success of prevention programs. Eat Disord 2001;9(3):261-5. https://doi.org/10.1080/10640260127553.

29. Yager Z, O'Dea JA. The role of teachers and other educators in the prevention of eating disorders and child obesity: What are the issues? Eat Disord 2005;13(3):261-78 https://doi.org/10.1080/10640260590932878.

30. Barton M. Childhood obesity: A life-long health risk. Acta Pharmacol Sin 2012;33(2):189-93 https://doi.org/10.1038/aps.2011.204.

31. Schwartz MB, Brownell KD. Obesity and body image. Body Image 2004;1(1):43-56. https://doi.org/10.1016/S1740-1445(03)00007-X.

32. Howard-Drake EJ, Halliday V. Exploring primary school headteachers' perspectives on the barriers and facilitators of preventing childhood obesity. J Public Health (Oxf) 2016;38(1):44-52. https://doi.org/10.1093/pubmed/fdv021.

33. Hirschman J, Chriqui JF. School food and nutrition policy, monitoring and evaluation in the USA. Public Health Nutr 2013;16(6):982-8. https://doi.org/10.1017/S1368980012004144

34. Jaime PC, Lock K. Do school based food and nutrition policies improve diet and reduce obesity? Prev Med 2009;48(1):45-53.

https://doi.org/10.1016/j.ypmed.2008.10.018

35. James DC. Factors influencing food choices, dietary intake, and nutrition-related attitudes among african americans: Application of a culturally sensitive model. Ethn Health 2004;9(4):349-67. https://doi.org/10.1080/1355785042000285375

36. Cairns G, Angus K, Hastings G, Caraher M. Systematic reviews of the evidence on the nature, extent and effects of food marketing to children. A retrospective summary. Appetite 2013;62:209-15. https://doi.org/10.1016/j.appet.2012.04.017.

37. Wolfson JA, Gollust SE, Niederdeppe J, Barry CL. The role of parents in public views of strategies to address childhood obesity in the United States. Milbank Q 2015;93(1):73-111.

https://doi.org/10.1111/1468-0009.12106

38. Barry CL, Gollust SE, McGinty EE, Niederdeppe J. Effects of messages from a media campaign to increase public awareness of childhood obesity. Obesity (Silver Spring) 2014;22(2):466-73. https://doi.org/10.1002/oby.20570.

39. Barry CL, Brescoll VL, Brownell KD, Schlesinger M. Obesity metaphors: How beliefs about the causes of obesity affect support for public policy. Milbank Q 2009;87(1):7-47. 
https://doi.org/10.1111/j.1468-0009.2009.00546.x.

40. Evans WD, Finkelstein EA, Kamerow DB, Renaud JM. Public perceptions of childhood obesity. Am J Prev Med 2005;28(1):26-32. https://doi.org/10.1016/j.amepre.2004.09.008.

41. Monterrosa EC, Campirano F, Tolentino Mayo L, Frongillo EA, Hernández Cordero S, Kaufer-Horwitz M, et al. Stakeholder perspectives on national policy for regulating the school food environment in mexico. Health Policy Plan 2015;30(1):28-38. https://doi.org/10.1093/heapol/czt094.

42. Park S, Choi BY, Wang Y, Colantuoni E, Gittelsohn J. School and neighborhood nutrition environment and their association with students' nutrition behaviors and weight status in Seoul, South Korea. J Adolesc Health 2013;53(5):655-62000000000000.

https://doi.org/10.1016/j.jadohealth.2013.06.002.

43. Ayoob KT. Solving childhood obesity: Parents may be more powerful than policies. Child Obes 2011;7(4):271-3. https://doi.org/10.1089/chi.2011.0400.edit.

44. Huang TT, Glass TA. Transforming research strategies for understanding and preventing obesity. JAMA 2008;300(15):1811-3.

https://doi.org/10.1001/jama.300.15.1811.

45. Sanchez E, Burns AC, Parker L. Local Government Actions to Prevent Childhood Obesity. Washington, DC: National Academies Press; 2009.

46. Bozlak C, Becker A, Herd J, Teitelman A, Viola J, Olson B, et al. An inter-governmental approach to childhood obesity in Chicago, Illinois. Int Public Health J 2015;7(1):7.

47. Branca F, Nikogosian H, Lobstein T. The Challenge of Obesity in the WHO European Region and the Strategies for Response: Summary. Copenhagen: World Health Organization; 2007.

48. Birch LL, Davison KK. Family environmental factors influencing the developing behavioral controls of food intake and childhood overweight. Pediatr Clin North Am 2001;48(4):893-907.

https://doi.org/10.1016/S0031-3955(05)70347-3.

49. Delormier T, Frohlich KL, Potvin L. Food and eating as social practice-understanding eating patterns as social phenomena and implications for public health. Sociol Health IIIn 2009;31(2):215-28.

https://doi.org/10.1111/j.1467-9566.2008.01128.x. 